\title{
Indigenous students: Barriers and success strategies-A review of existing literature
}

\author{
Heather Joyce Nelson, Twana Lee-Ann Cox-White, Beverlee Ann Ziefflie \\ Saskatchewan Polytechnic, Regina, Saskatchewan, Canada
}

Received: August 28, 2018

Accepted: November 1, 2018

Online Published: November 22, 2018

DOI: $10.5430 /$ jnep.v9n3p70

URL: https://doi.org/10.5430/jnep.v9n3p70

\begin{abstract}
There are many factors that effect the post-secondary completion rate of Indigenous students. The Indigenous student completion rate is a reflection of the number of students entering post-secondary education but is significantly affected by withdrawal rates (institutional withdrawals and student voluntary withdrawals). In the Saskatchewan Polytechnic School of Nursing, the Indigenous student withdrawal rate was $4.2 \%$ higher than the total nursing student population. Lower success rates among Indigenous students is a concerning issue in nursing programs. Continuing to operate programs and teach in the same fashion is not improving success rates. The Truth and Reconciliation Commission of Canada: Calls to Action (2012) highlighted the need to examine strategies and develop policies to enhance Indigenous student success. To this end, recent literature was reviewed to determine trends among Indigenous nursing students, their struggles, and more importantly, the successful strategies currently being implemented. Indigenous peoples are not a homogenous group; rather, they are a mosaic of cultures, languages and nations. The authors examined the literature to determine key factors that enabled or prevented the success of post-secondary Indigenous students. Twenty-one articles on current research regarding Indigenous student success facilitators and barriers were examined. These articles encompassed research from Canada, the United States, Australia and New Zealand. The purpose of this literature review was to identify themes and gaps, drive positive change in education, and guide future research. The research team found four common themes: academic preparedness, cultural safety, intrinsic student factors, and student support.
\end{abstract}

Key Words: Indigenous, Students, Barriers, Success, Post-secondary, Nursing

\section{INTRODUCTION}

While Indigenous children "were being demeaned in the schools and their culture and language were being taken away from them and they were being told that they were inferior, they were pagans, that they were heathens and savages and that they were unworthy of being respected — that very same message was being given to the non-aboriginal children in the public schools as well." ${ }^{[1]}$ - Justice Murray Sinclair

High levels of homelessness, crime, poor health, and low education levels ${ }^{[2]}$ presented a variety of challenges for In- digenous peoples of Canada. These challenges, rooted in poverty, triggered a cycle. "The higher the level of poverty, the lower the level of educational attainment: low levels of educational attainment, in turn, increase the likelihood of poverty". ${ }^{[2]}$ The identification of barriers to educational attainment has the potential to be a first step towards breaking the cycle.

There is a large gap in post-secondary educational achievements of Indigenous peoples of Canada compared to those of non-Indigenous ancestry. Statistics Canada ${ }^{[3]}$ reported,

${ }^{*}$ Correspondence: Heather Joyce Nelson; Email: heather.nelson@saskpolytech.ca; Address: Saskatchewan Polytechnic, Regina, Saskatchewan, Canada. 
$33.9 \%$ of Indigenous peoples of Canada age 25-64 completed post-secondary education as compared to a $54 \%$ completion rate for all Canadians in the same age group. In Saskatchewan, the Indigenous population has a 18.5\% lower post-secondary completion rate compared to the nonIndigenous population. ${ }^{[4]}$ At Saskatchewan Polytechnic (a medium sized applied research institution), the average nursing student withdrawal rate (discontinued by the institution or student voluntary withdrawals) for the years encompassing 2011-2016 was 12.8\% among Indigenous students and
$8.6 \%$ among the total nursing student population (see Tables 1 and 2). This is particularly important because educational attainment correlates directly with employment. In the recent Statistics Canada (2016) survey, the median income rose with each level of educational attainment. ${ }^{[4]}$ For example, on average Indigenous peoples aged 25-64 with a bachelor's degree or higher earned 200\% more than Indigenous peoples with only a high school education. ${ }^{[4]}$ Therefore, the gap in educational attainment of Indigenous peoples correlated with a gap in income.

Table 1. Enrolment and withdrawals for Saskatchewan Polytechnic School of Nursing: Practical Nursing and Saskatchewan Collaborative Bachelor Science of Nursing: All students

\begin{tabular}{llllll}
\hline Total-All Students & $\mathbf{2 0 1 1 - 2 0 1 2}$ & $\mathbf{2 0 1 2 - 2 0 1 3}$ & $\mathbf{2 0 1 3 - 2 0 1 4}$ & $\mathbf{2 0 1 4 - 2 0 1 5}$ & $\mathbf{2 0 1 5 - 2 0 1 6}$ \\
\hline Enrollment & 185 & 247 & 258 & 245 & 219 \\
Withdrawn & 15 & 21 & 19 & 28 & 17 \\
\% Withdrawn & $8 \%$ & $9 \%$ & $7 \%$ & $11 \%$ & $8 \%$ \\
Exited by Institution & 11 & 13 & 8 & 13 & 6 \\
Voluntary Withdrawal & 4 & 8 & 11 & 15 & 11 \\
\hline
\end{tabular}

Table 2. Enrolment and withdrawals for Saskatchewan Polytechnic School of Nursing: Practical Nursing and Saskatchewan Collaborative Bachelor Science of Nursing: Indigenous students

\begin{tabular}{llllll}
\hline Total-Indigenous Students & $\mathbf{2 0 1 1 - 2 0 1 2}$ & $\mathbf{2 0 1 2 - 2 0 1 3}$ & $\mathbf{2 0 1 3 - 2 0 1 4}$ & $\mathbf{2 0 1 4 - 2 0 1 5}$ & 2015-2016 \\
\hline Indigenous Enrollment & 16 & 43 & 255 & 50 & 48 \\
Indigenous Withdrawn & 1 & 8 & 8 & 7 & 5 \\
\% Indigenous Withdrawn & $6 \%$ & $19 \%$ & $15 \%$ & $14 \%$ & $10 \%$ \\
Indigenous Exited by Institution & 1 & 7 & 7 & 5 & 2 \\
Indigenous Voluntary Withdrawal & 0 & 1 & 1 & 2 & 3 \\
\hline
\end{tabular}

Overcoming the "dispositional, situational, and systemic obstacles" ${ }^{[5]}$ faced by Indigenous peoples is critical for postsecondary institutions if the cycle of poverty and its consequences are to be addressed. Post-secondary institutions across Canada must address the common barriers faced by Indigenous peoples to enter and successfully complete postsecondary education, while embracing the Truth and Reconciliation Commission (TRC) Calls to Action. that address Indigenous education.

The first step in addressing these barriers was to determine what was already known about Indigenous students' barriers and success strategies through a search of the literature. This literature review examined current research related to existing barriers and success strategies that affect Indigenous student success in post-secondary educational institutions. It is hoped that this summary provides post-secondary institutions with insights for new initiatives and strategies leading to greater success while addressing the Calls to Action of the TRC. The TRC ${ }^{[6]}$ Calls to Action 23(i) states, "We call upon all levels of governments to: Increase the number of [Indigenous] professionals working in the health-care field." This highlighted the importance of increasing Indigenous nursing student graduates and the number of Indigenous people working in the field of nursing.

\section{METHOD}

\subsection{Literature search}

Multiple sources were reviewed to capture relevant information. The databases searched were the Cumulative Index of Nursing and Allied Health Literature (CINAHL), Canadian Business and Current Affairs (CBCA), the Educational Resources Information Center (ERIC), and Education Source databases. The keywords used included aboriginal, native peoples, Inuit, Métis, Native North Americans, Indigenous, Aborigines, Eskimos, American Native Continental Ancestry Group, Oceanic Ancestry Group, students and education (nursing students, health science students, medical students, physical therapy students, social work students and phar- 
macy students), success, failure, academic failure, academic achievement, academic underachievement, attrition, student dropouts.

The limiters for this literature review included 2012-2017 and post-secondary Indigenous students. This five-year limiter eliminated some important older studies, but was selected so as to focus on the recent changes in post-secondary education that have occurred post $\mathrm{TRC}^{[6]}$ Calls to Action. Indigenous, a Canadian term used in this review, included those who identify as First Nations (original inhabitants of Canada), Métis (people of mixed European and Indigenous ancestry), and Inuit (Indigenous peoples who live in the northern parts of Canada). ${ }^{[7]}$ This term was selected by Indigenous peoples to describe themselves. The term, Aboriginal, was used by the Government of Canada, while Aborigine or Indian may be used in other countries. In order to include a broad range of information, studies from New Zealand and Australia were also included.

A total of 154 articles were located in the initial search. A number of articles were excluded after a review due to their lack of relevance or inability to locate the article. After exclusions, 57 articles remained and were scanned to determine whether they were appropriate and specific to the criteria for the literature review. Articles were excluded due to wrong population (non-Indigenous or nursing instructor perspective), and insufficient data related to Indigenous student barriers and success strategies. 21 were deemed suitable for this review due to their relevance on the topic of Indigenous Post-Secondary successes and barriers in postsecondary success. From the literature, fourteen research studies, four literature reviews, one book, one paper, and one thesis were examined. Twelve of these articles discussed Nursing or Health Education programs, seven discussed general post-secondary success, one examined an education program, and one looked at elementary education. Six of the articles were from Canada, six from the United States, one study accounted for both United States and Canada, and eight articles were from Australia and New Zealand.

\section{RESUlTS}

In examination of the data from each of the articles, four themes naturally emerged: academic preparedness, cultural safety, intrinsic student factors, and student supports. Each of the themes could be viewed as a success strategy when present or a barrier when lacking. Further discussion among the authors clarified the themes and resulted in ten subthemes.

(1) Academic Preparedness

(2) Cultural Safety
A. Cultural Experience

B. Indigenization of Post-Secondary Institutions

C. Cultural Identity

(3) Intrinsic Student Factors
A. Resilience
B. Self-confidence
C. Social Isolation

(4) Student supports
A. Mentorship
B. Supportive Staff
C. Family Supports
D. Financial Supports

The themes and sub-themes are discussed in this literature review.

\subsection{Academic preparedness}

Inadequate educational preparation as a barrier to student success was a common theme identified. ${ }^{[8-11]}$ This reflected a variety of issues. Indigenous students often had longer gaps between high school and post-secondary education, creating distance between their education and current institutional expectations and norms. ${ }^{[2,5,9,10]}$ Foxall $^{[9]}$ further noted that high school students needed to be encouraged to take course work that would be helpful if they wanted to enter a health care field. Due to the low rates of secondary completion among the Indigenous populations, families often did not understand the requirements for post-secondary students to be successful or know how to support their family members through school. ${ }^{[9]}$

\subsection{Cultural safety}

Cultural safety was identified as a second theme and was the culmination of generations of lived experiences, both positive and negative. It was further divided into three sub-themes: cultural experience, Indigenization of post-secondary institutions, and cultural identity. Each of these sub-themes was prevalent in the literature studied and noted as an important factor in student success.

\subsubsection{Cultural experience}

Cultural experience in post-secondary education influenced students' perceptions of belonging, impacting their success. Many Indigenous students experienced racism throughout their lives and this continues today in post-secondary institutions. This coloured their encounters as they made their way through their educational experiences. A number of studies explored barriers to success related to underlying racism in the classroom. Derogatory attitudes, including racist comments, slang, and inferences from both students and staff were identified as barriers for Indigenous students. ${ }^{[8]}$ Additionally, events that were culturally exclusive, insensitive, and non-caring were reported by Gilmon. ${ }^{[12]}$ It was also 
found that some staff reportedly allowed racist discussions to take place during class. ${ }^{[9]}$ These events were significant barriers to student success.

\subsubsection{Indigenization of post-secondary institutions}

The importance of Indigenization was examined in a number of studies. For this review, Indigenization of post-secondary institutions was seen as adding Indigenous content to course material, enhancing the educational environment, and ensuring that Indigenous people were employed by educational institutions. For centuries, Indigenous knowledge, culture, and values were excluded from formal education at all levels. ${ }^{[2]}$ The importance of including this information in formal education was a key step to reconciliation as outlined by various Calls to Action. ${ }^{[6]}$ Four studies $^{[8,13-15]}$ in this literature review supported the TRC assertion that Indigenization of post-secondary institutions was essential. Predictably, having a culturally diverse curriculum in a culturally-diverse setting was important. ${ }^{[13]}$ Additionally, teaching cultural competence in nursing school was a benefit to all students. ${ }^{[13]}$ Teaching language and culture within the curriculum and including Indigenous health promoted success and pride among students. ${ }^{[8,14]}$ Students recognized when instructors respected Indigenous culture and they experienced more academic success. ${ }^{[12]}$ Indigenous nurse academics and Indigenous staff supports were beneficial as role models and for their role in promoting success. ${ }^{[8,15]}$ The articles reviewed agreed on the importance of Indigenizing both the environment and curriculum, while ensuring Indigenous role models were present among staff members. ${ }^{[8,13-15]}$

\subsubsection{Cultural identity}

Cultural identity was shown to be an important factor in student success. ${ }^{[12,16,17]}$ Students who identified as having a weak cultural connection and identity faced significant barriers to success. Ethnic identity provided a sense of comfort and belonging. ${ }^{[17]}$ On the other hand, concerns about cultural safety were seen as a significant barrier. ${ }^{[17]}$ Gilmon $^{[12]}$ found incongruences between Indigenous definitions of educational success versus non-Indigenous peoples, leading Indigenous students to experience stress and a feeling of walking in two different worlds. ${ }^{[12]}$ A strong connection with Indigenous culture was shown to be a support, but cultural safety and the conflict of attending school in a Euro-centric model with a culturally Indigenous home life continued to be an issue identified in the literature.

\subsection{Intrinsic student factors}

Intrinsic student factors referred to inner traits that affected a student's ability to succeed. It was important to consider the long-term effects of systemic racism through the many injustices that Indigenous people have faced including the

Published by Sciedu Press
Indian Act passed by the Canadian parliament, residential schools, and the Canadian government strategy in the 1960s to adopt Indigenous children into white homes, also known as the Sixties Scoop. ${ }^{[5]}$ These larger societal factors led to the intrinsic barriers that continue to exist for many Indigenous peoples today. Through this literature review, the authors aimed to examine the unique individual barriers that many Indigenous students face, but it is acknowledged that larger societal issues were at play. Intrinsic barriers were divided into three categories: resilience, self-confidence and social isolation.

\subsubsection{Resilience}

Resilience, or the ability for students to move forward when schooling was difficult, boring, or other factors interfered, significantly influenced student success. ${ }^{[18]}$ This intrinsic factor allowed students to continue in spite of setbacks. ${ }^{[18]}$ Indigenous students showed lower motivation when the class content was viewed as not being immediately relevant to their lives or careers. ${ }^{[19]}$ Furthermore, the definition of success was not the same for many Indigenous students as it was for non-Indigenous students. ${ }^{[12]}$ This, and the relationship to resilience, warrants further examination.

Building resilience and inner determination factored into program completion. ${ }^{[11]}$ A number of strategies increased resilience for Indigenous students. Strengthening hope through mentorship and instructor support increased potential success. $^{[20]}$ Feeling respected by others also increased resilience. ${ }^{[21]}$ One study found that assessing self-regulation of motivation was a predictor of end of semester success. Further, efforts to improve self-regulation of motivation would build students' resilience when content was difficult or boring. ${ }^{[18]}$ In summary, resilience was not a fixed character trait; however, it could be increased with hope, respect, and building inner determination.

\subsubsection{Self-confidence}

Confidence was defined as the belief that a person could and would succeed in a given area. Confidence, when lacking, was a barrier and was seen as important to build in students ${ }^{[9,16]}$ Starting from enrollment, lack of confidence and fear of failure were found to be substantial barriers to success. ${ }^{[9]}$ Students who felt strongly that they were in the right program were more confident about seeking assistance and handling the stresses of the course work load. ${ }^{[22]} \mathrm{A}$ study by Whitley ${ }^{[19]}$ indicated teachers felt that Indigenous students had a low self-concept related to family expectations regarding education. Additionally, another study found that an Indigenous student's definition of success could be inconsistent with teacher expectations. ${ }^{[12]}$

A number of strategies were shown to be useful in improving 
student confidence. Building student confidence early in a program was important and effective. This could be accomplished by implementing simple assessment tasks early in the program, which built confidence and a sense of selfworth and esteem. ${ }^{[15]}$ Alternately, Gallop and Bastien ${ }^{[16]}$ stated clear expectations and feedback were important but overly negative feedback increased withdrawal rates. These two strategies could be combined by providing simple early assessments and then following up with more challenging assignments to build confidence in a student's ability to complete post-secondary education. Both Foxall ${ }^{[9]}$ and Gallop and Bastien ${ }^{[16]}$ examined mentorship as an important method of building confidence. Another successful strategy was of fering bridging courses that helped students improve knowledge and skills before entering an educational program. ${ }^{[23]}$ Building a student's confidence was essential for Indigenous students through appropriate assignments, feedback, and mentorship..$^{[9,15,16]}$

\subsubsection{Social isolation}

Indigenous students often experienced social isolation due to factors such as geographic separation and cultural differences. ${ }^{[10]}$ Two studies examined the number of Indigenous students who were required to relocate far distances from their families, communities, and familiar cultures to attend post-secondary institutions. ${ }^{[17,24]}$ This had a negative effect on success due to geographic separation and decreased social support.

Building relationships with peers and educational staff was a key to reducing social isolation and supporting success. ${ }^{[9,11,14,19]}$ Indigenous students reported that positive relationships with faculty who were aware of their unique needs and struggles supported their achievements. Faculty who were flexible and shifted away from Euro-centric educational culture and pedagogies, while demonstrating sensitivity to the unique issues that Indigenous students faced, had a positive impact. ${ }^{[19,21]}$ Planned activities, such as potlucks and social outings, were studied by Rearden. ${ }^{[25]}$ Reducing isolation by building relationships, social learning, and planned outings boosted potential success. While bridging, preparatory sessions and courses were mentioned later as an academic support; they also created a social circle and support. ${ }^{[26]}$

\subsection{Student supports}

Many researchers examined Indigenous student supports. ${ }^{[9,10,13,15,16]}$ Indigenous peoples often included extended family and people from their home community as their direct support network. Their support network could be fractured due to the need to relocate to attend post-secondary education. Four sub-themes emerged from the literature review: mentorship, supportive staff, family supports, and financial supports. When missing, student success was negatively impacted.

\subsubsection{Mentorship}

Mentorship encompassed engaging fellow students or alumni as role models. This strategy increased student success in a number of studies..$^{[9,10,16]}$ Mentorship methods varied from study to study, however, current research showed that providing peer mentors with the same cultural background as the student was effective. ${ }^{[12]}$ Engaging former students as mentors was also successful. ${ }^{[15]}$ Peer mentorship was identified as a positive strategy by Thurston $\&$ Mashford. ${ }^{[24]}$ A mentorship circle guided this type of mentorship, giving students an opportunity to share their challenges and successes. ${ }^{[27]}$ On the other hand, Rearden ${ }^{[25]}$ found low numbers of students participated in the mentorship program during their studies and the reviews were mixed with comments ranging from not helpful to very helpful. Providing Indigenous students with mentors, and creating opportunities for them to share their experiences, was a clear strategy to support success.

\subsubsection{Supportive staff}

Supportive staff can make the difference between student success and failure. Three recent studies showed that the relationship between Indigenous students and the faculty and staff was crucial to success. ${ }^{[19,21,25]}$ Curtis et al. ${ }^{[23]}$ specifically examined the impact of a positive reciprocal relationship between students and clinical educators. Supportive staff played a significant role. The importance of having staff members with a similar cultural background to support and encourage students was examined in one Alaskan study. ${ }^{[25]}$ The literature presented different ideas on how to build these relationships. Faculty support was provided through staff who believed in students, provided clear expectations, and expected accountability. Instructors who believed in the students made a difference between success and failure. ${ }^{[16,19]}$ One study examined the importance of a pre-interview to deal with challenges, expectations, and concerns. ${ }^{[15]} \mathrm{Com}-$ municating clear expectations, and providing feedback was an important factor. ${ }^{[16,19]}$ Equally as important, Plater ${ }^{[15]}$ discussed the damaging effects of ignoring lateness and not holding students accountable for underperforming, which led to an unhealthy co-dependency. Holding students accountable, having clear expectations, and having instructors who believed in them, supported student success.

\subsubsection{Family supports}

Community and family support were seen as important influencers. This support was often lacking for a variety of reasons; however, its importance cannot be underestimated for Indigenous students. ${ }^{[21]}$ Gilmon $^{[12]}$ found that family 
and self-care were also critical. As discussed in the social isolation section, Indigenous students often had to leave their family, community and support system to attend school, significantly reducing their social supports and often creating a substantial barrier. In addition, Indigenous students were often the caregiver for other family members in their community, another barrier resulting in a variety of emotions including guilt, anger, and frustration. ${ }^{[17]}$ Pressure to participate in community and family activities, and norms that interfered with schooling and educational expectations, compounded the problem and presented another barrier. ${ }^{[11]}$ Of note was that, in many cases, Indigenous students entering post-secondary institutions were the first in their family to do so. Many Indigenous families had negative experiences with past educational systems and they often saw little value in post-secondary education. A lack of trust in the system as a whole created another barrier. ${ }^{[13]}$ Despite these added family pressures, the absence of family was a significant stressor. ${ }^{[10]}$ Encouraging family members to participate in the student's experience and inviting them to participate in social activities was identified as an important strategy. This could holistically promote relationships and support for the family. ${ }^{[21]}$

\subsection{Financial supports}

Financial pressures were a concern for all students and this was especially true of the Indigenous student population. Indigenous students listed lower socio-economic class as an added stress. ${ }^{[17]}$ This financial pressure was also found in studies by Thurston and Mashford-Pringle ${ }^{[24]}$ and Slovacek et al. ${ }^{[10]}$ Students were not prepared for the reality of finances required to attend a post-secondary institute. ${ }^{[9,13]}$ Having a plan for financial assistance improved success rates. ${ }^{[10]}$ Milne et al. ${ }^{[21]}$ reaffirmed this point by confirming that financial support was important to success. Being financially unprepared was identified as a barrier.

\subsection{Gaps}

Four gaps exist within the literature review. These include the five-year limiter, the nursing specific lens, Indigenous peoples viewed as a homogenous group, and the possible lack of collaboration with Indigenous researchers.

The five-year limiter was imposed by the authors to encompass the effects of the TRC Calls to Action, which may have excluded valuable research conducted outside of the chosen time frame. The Calls to Action mandate is to "mobilize all levels of government, organizations, as well as individuals to make concrete changes in society". [6] The authors recognize that it will take time for the Calls to Action to be instituted and researched therefore, this change will continue over an extended period of time. Another potential gap is the authors chose to focus on nursing education for their research and, while some articles on general post-secondary education were utilized, other articles may have been overlooked.

Additionally, a gap within the research was the fact that Indigenous students are a diverse group in themselves. They have different life experiences. Many of these studies examined Indigenous peoples as a homogenous group. Moreover, some of the studies were focused on Australian Aborigines and while there are many similarities, it cannot be assumed that the same barriers and success strategies exist for Indigenous students in Canada. Further study to determine the barriers and successes among North American Indigenous students is a priority, as is addressing the wide variation of influencing factors among Indigenous peoples.

Reconciliation between Indigenous peoples and nonIndigenous peoples is based on relationship building. There is a potential gap as some of the researchers may have neglected to collaborate with Indigenous peoples. Participation and collaboration of Indigenous peoples within research is imperative to foster trust and openness, which will lead to rich and authentic findings. Despite these gaps, the authors feel that data collected is relevant and significant.

\section{Discussion}

The Indigenous peoples of Canada have faced numerous injustices due to colonization. The education system, in particular residential schools, has had lasting intergenerational, negative, and systemic effects on many Indigenous peoples. ${ }^{[2]}$ The overwhelming distrust of education that many Indigenous peoples continue to experience has a profound effect on the attainment of post-secondary education. ${ }^{[6]}$

Through the Truth and Reconciliation Commission, the Federal government and post-secondary institutions were called to address the fractured relationship between the Indigenous people and the education system. ${ }^{[6]}$ Although it was challenging, the strategies highlighted in this review provided insights to how post-secondary institutions can embrace, facilitate, and narrow the educational gap between Indigenous and non-Indigenous Canadians. Are post-secondary intuitions equipped and willing to decolonize the long standing, traditional practices and policies of academia that compete with strategies supporting Indigenous educational success? Can post-secondary institutions truly combat the systemic colonized cultural norms that run deep within Canada? Will holistic strategies supporting Indigenous educational success have a tangible impact on the systemic barriers that Indigenous peoples face?

Providing Indigenous students with appropriate supports is 
vital to increasing Indigenous student completion rates. Instructors have a role in building confidence and relationships with Indigenous students in a variety of ways. Providing clear expectations and feedback while ensuring that feedback is constructive, improves confidence. ${ }^{[14]}$ Additionally, instructors who are encouraging and believe in student's ability to be successful, foster confidence. ${ }^{[10]}$ Relationship building is enhanced when instructors demonstrate respect for Indigenous culture. ${ }^{[12]}$ Furthermore, mentorship with fellow students and staff encourages successful completion. ${ }^{[9,16]}$ Arranging mentors with students in later years and with recently graduated students is a positive success building strategy. ${ }^{[16]}$ Also, hiring Indigenous staff, where possible, provides a mentor among the staff. ${ }^{[8,15]}$ Moreover, building relationships with peers and staff through planned social outings, potlucks, and social learning aided in student success. ${ }^{[25]}$ Finally, removing barriers by ensuring that the proper financial assistance is available for students, increases success. ${ }^{[21]}$ Implementing the strategies suggested in the literature will aid in success and remove many barriers that Indigenous students face.

One might contend that the strained and inequitable relationship between Indigenous peoples and the educational system was created long before students entered post-secondary education. Strategies to promote confidence, resiliency, and

\section{REFERENCES}

[1] Kennedy M. Teachings about aboriginals 'simply wrong', says Murray Sinclair. Ottawa Citizen. 2015 May 29. Available from: https: //ottawacitizen.com/news/politics/teachings-about -aboriginals-simply-wrong-says-murray-sinclair

[2] Silver J. Aboriginal adult education: Combating poverty and colonization. In J. Silvers (Ed.), Moving forward, giving back: Transformative Aboriginal adult education. Halifax, NS and Winnipeg, MB. Fernwood Publishing. 2013; 1-16.

[3] Statistics Canada. Education in Canada: Key results from the 2016 Census. The Daily. 2017. Available from: https://www150.statcan.gc.ca/n1/daily-quotidien/1 71129/dq171129a-eng.htm

[4] Arora A. First Nations, Métis and Inuit statistics: The way forward [PowerPoint slides]. 2018. Available from: https://www150.statcan.gc.ca/n1/en/pub/11-631-x/1 $1-631-x 2018005-$ eng $\cdot$ pdf?st=4IVADqk0

[5] MacKinnon S. Healing the spirit first: Aboriginal second-chance learners in three inner city programs. In J. Silvers (Ed.), Moving forward, giving back: Transformative Aboriginal adult education. Halifax, NS and Winnipeg, MB. Fernwood Publishing. 2013; 49-16.

[6] Truth and Reconciliation Commission of Canada. Truth and reconciliation commission of Canada: Calls to action. 2015. Available from: http://www.trc.ca/websites/trcinstitution /File/2015/Findings/Calls_to_Action_English2.pdf academic preparedness must also be addressed at a societal level. The TRC's Calls to Action are directives to assist with social change, behaviours, beliefs, and constructs. The social and systemic changes that must occur will take time and face many unique obstacles.

\section{Conclusion}

Post-secondary Indigenous students face many obstacles to successful attainment of post-secondary education. After reviewing current literature, the authors categorized the barriers under four themes: academic preparedness, cultural safety, intrinsic student factors, and student supports.

Barriers can successfully be overcome by providing adequate funding and fostering the development of personal and effective relationships between instructors and Indigenous students. Educational institutions must provide safe and culturally competent spaces and incorporate Indigenous knowledge and culture into Canada's post-secondary institutions. Further research into success strategies supporting Indigenous student success is warranted. In tandem, the deeply rooted dispositional, situational, and systemic obstacles that Indigenous students face must be addressed.

\section{CONFlicts OF INTEREST Disclosure}

The authors declare that there is no conflict of interest.
[7] Parrott Z. Indigenous peoples in Canada. In The Canadian Encyclopedia. 2018. Available from: https://www.thecanadianencyc lopedia.ca/en/article/aboriginal-people

[8] Best O, Stuart L. An Aboriginal nurse-led working model for success in graduating Indigenous Australian nurses. Contemporary Nurse: A Journal for the Australian Nursing Profession. 2014 Jan; 48(1): 59-66. https://doi.org/10.1080/10376178.2014.11081927

[9] Foxall D. Barriers in education of Indigenous nursing students: A literature review. Nursing Praxis in New Zealand. 2013 Nov; 29(3): 33-39.

[10] Slovacek S, Whittinghill J, Flenoury L, et al. Promoting minority success in the Sciences: The minority opportunities in research programs at CSULA. Journal of Research in Science Teaching. 2011 Dec; 49(2): 199-217. https://doi .org/10.1002/tea. 20451

[11] Slatyer S, Cramer J, Pugh J, et al. Barriers and enablers to retention of Aboriginal diploma of nursing students in western Australia: An exploratory descriptive study. Nurse Education Today. 2016 July; 42: 17-22. https: \doi.org/10.1016/j.ndet.2016.03.026

[12] Gilmon M. Cultural diversity and the experiences of Alaska native nursing students. 2012 Jan. Available from: http://digshcolarship.unco.edu/cgi/viewcontent.cgi? article $=1130 \&$ context $=$ dissertations

[13] Graham C, Phillips S, Newman S, et al. Baccalaureate minority nursing students perceived barriers and facilitators to clinical education practices: An integrative review. Nursing Education Perspectives. 2016 May; 37(3): 130-137. 
[14] Kitchen J, Hodson J. Living alongside: Teacher educator experiences working in a community-based Aboriginal teacher education program. Canadian Journal of Education. 2013; 36(2): 144-175.

[15] Plater S. "For the life of me, I can't see why those students were let go on so long": Educating the educators, Aboriginal and Torres Strait Islander-style. Australian Journal of Indigenous Education. 2012 Dec; 441(2): 156-161.

[16] Gallop C, Bastien N. Supporting success: Aboriginal students in higher education. Canadian Journal of Higher Education. 2016; 46(2): 206-224.

[17] Rawana J, Sieukaran D, Nguyen H, et al. Development and evaluation of a peer mentorship program for Aboriginal university students. Canadian Journal of Education. 2015; 38(2): 1-34. https: //doi.org/10.2307/canajeducrevucan.38.2.08

[18] Hoops L, Yu S, Burridge A, et al. Impact of a student success course on undergraduate academic outcomes. Journal of College Reading and Learning. 2015 May; 45(2): 123-146.

[19] Whitley J. Supporting educational success for Aboriginal students: Identifying key influences. McGill Journal of Education (Internet). 2014; 49(1): 155-181.

[20] Charbonneau-Dahlen B. Hope: The dream catcher-medicine wheel retention model for diverse nursing students. Journal of Theory Construction \& Testing. 2015 Sept; 19(2): 47-54.

[21] Milne T, Creedy D. West R. Integrated systematic review on educational strategies that promote academic success and resilience in undergraduate Indigenous students. Nurse Education Today. 2016; 36: 387-394. PMid:26521033 https://doi .org/10.1016/j.ne dt. 2015.10.008

[22] Sopoaga F, van der Meer J. Investigating factors that influence success of Pacific students in first-year health sciences at university in New Zealand. The New Zealand Medical Journal. 2012 March; 125(1352): 28-38.

[23] Curtis E, Wikaire D, Jiang Y, et al. Open to critique: Predictive effects of academic outcomes from a bridging/foundation programme on first-year degree-level study. Assessment \& Evaluation in Higher Education. 2017; 42(1): 151-167. https://doi.org/10.1080/ 02602938.2015 .1087463

[24] Thurston J, Mashford-Pringle A. Nursing \& Indigenous integration. Journal of Nursing Education \& Practice. 2015; 5(10): 9-15. https://doi.org/10.5430/jnep.v5n10p9

[25] Rearden A. Recruitment and retention of Alaska natives into nursing: Elements enabling educational success. Journal of Cultural Diversity. 2012; 19(3): 72-78.

[26] Marshall S, Zhou M, Gervan T, et al. Sense of belonging and firstyear academic literacy. The Canadian Journal of Higher Education. 2012; 42(3): 116-142.

[27] Felton-Busch C, Maza K, Ghee M. et al. Using mentoring circles to support Aboriginal and Torres Strait Islander nursing students: Guidelines for sharing and learning. Contemporary Nurse: A Journal for the Australian Nursing Profession. 2013 Dec; 46(1): 135-138. 